The caffeine metabolite AFMU appears to be very labile under physiological conditions. Even if specimens are adjusted immediately to $\mathrm{pH} \leqslant$ 3.0 and frozen, there would still be a loss of AFMU in the more basic urines prior to voiding. Acidifying the urine by giving ammonium chloride might help but would add additional steps to the process of using caffeine to determine acetylation phenotype.

The poor aqueous solubility of $1 \mathrm{X}$ is also a potential problem. Achieving reproducible results may be difficult when measuring concentrations of a suspended rather than a dissolved substance. Redissolution of $1 \mathrm{X}$ in the urine by raising temperature or $\mathrm{pH}$ would accelerate AFMU degradation if both are measured from the same sample. This instability of AFMU and poor aqueous solubility of $1 \mathrm{X}$ may lead to a fall in the concentration of both compounds during the

\section{References}

Grant, D. M., Tang, B. K. \& Kalow, W. (1984a). A simple test for acetylator phenotype using caffeine. Br. J. clin. Pharmac., 17, 459-464.

Grant, D. M., Tang, B. K. \& Kalow, W. (1984b). Factors affecting urinary levels of an acetylated caffeine metabolite in man. Canadian Fed. Biol. analysis with fortuitously little change in their ratio much of the time. The instability of AFMU and poor solubility of $1 \mathrm{X}$ may also explain the intra-subject phenotype variability (Hardy $e t$ al., 1988) when caffeine was used as a test marker and suggests caution in the use of this phenotyping method.

This research was partially supported by N.I.H. Grant AM32869.

\section{B. LORENZO \& M. M. REIDENBERG}

Departments of Pharmacology and Medicine, Cornell University Medical College, 1300 York Avenue, New York, NY 10021, U.S.A.

Received 8 February 1989 , accepted 6 April 1989

Soc. Proceedings, 27, 123 (abstract).

Hardy, B. G., Lemieux, C., Walker, S. E. \& Bartle, W. R. (1988). Interindividual and intraindividual variability in acetylation: characterization with caffeine. Clin. Pharmac. Ther., 44, 152-157.

\title{
Drug treatment of intermittent claudication
}

I have read with great interest the article 'Drug. treatment of intermittent claudication' by Cameron et al. (1988). May I comment on the following: (1) the published results from studies of oxpentifylline; (2) the proposed guideline for clinical studies in patients with occlusive arterial disease.

From a scientific point of view it appears hardly understandable that a paper submitted in April 1988 presents the knowledge of 1985, thus neglecting more recent publications which might have a considerable bearing on the evaluation of the drugs concerned.

In relation to the oxpentifylline study done by Porter et al. (1982) it is claimed that exclusion of $36 \%$ of patients from final analysis resulted in bias. In 1987, Gillings et al. published an intentionto-treat analysis of the data in question which confirmed the earlier findings from endpoint analysis, thus refuting the bias presumed. The list of placebo-controlled studies omits two studies in which oxpentifylline was tested against pharmacologically active material (adenosine, nylidrin). However, no mention was made of the dosage for these substances, both of which were deliberately used at a level as low as $\mathbf{3 m g}$ three times daily so that they may be considered equal to placebo. The FDA accepted the nylidrin study (Acetto, 1982) as pivotal, after they had inspected the study centre and examined the original data.

One would expect that a review article appearing in 1988 would give now generally used evaluation statistics such as confidence intervals, in addition to mean values. This type of information was presented for ketanserin but not for oxpentifylline. The respective data were reported by Roessner \& Mueller in 1987. Based on 252 patients (seven studies), Cameron et al. (1988) reported a therapeutic effect of $65 \%$ for oxpentifylline, as compared with placebo. With a variation of results of similar order, the respective $95 \%$ confidence interval would be in the range of 
$50-80 \%$. It thus appears unlikely that oxpentifylline should have yielded results below the $50 \%$ mark.

The above were placebo-controlled doubleblind studies. In these, the required sample size, as well as alpha and beta, has to be defined beforehand, depending on what difference in treatment effect between the groups is considered relevant. Premature discontinuation of treatment as hinted by Cameron et al. (1988), is not possible under such circumstances.

The authors say that 'The results of clinical trials which convince prescribers and even regulatory authorities do not seem to be acceptable to critical reviewers.' It is generally known that decisions of regulatory bodies such as the DHSS or FDA are based on the opinion of an external expert committee. Leaving the author's assertions uncommented would have meant to cast doubt on that expert committee's competence, which is certainly not admissible.

The authors have worked out acceptable guidelines for clinical testing in patients with occlusive arterial disease. However, we feel they should be complemented in various aspects, mainly the following:

1. Besides familiarizing a patient with the testing procedure (treadmill exercise), the main purpose of a run-in phase is to establish walking distance stability before the patient is included in the double-blind observation phase. A run-in phase should therefore extend over a minimum of 4-6 weeks and involve the use of appropriate criteria for establishing walking distance stability and, ideally, a standardised exercise procedure.

2. Exercises on the treadmill to determine a patient's exercise capacity must be done under strictly standardised conditions. Interindividual

\section{References}

Accetto, B. (1982). Beneficial hemorheologic therapy of chronic peripheral arterial disorders with pentoxifylline: Results of a double-blind study versus vasodilator-nylidrin. Am. Heart J., 103, 864-869.

Blair, S. N. (eds) (1986). Guidelines for exercise testing and prescription, $\mathrm{p}$ 157. Philadelphia: Lea and Febiger.

Cameron, H. A., Waller, P. C. \& Ramsay, L. E. (1988). Drug treatment of intermittent claudication: A critical analysis of the methods and findings of published clinical trials, 1965-1985. Br. J. clin. Pharmac., 26, 569-576.

EC Guidelines (1984). Clinical investigation of drugs for the treatment of chronic peripheral arterial diseases. J. European Communities, 5, Annex XI. adjustments of treadmill velocity with corresponding workload differences between patients cannot be accepted (Blair et al., 1986). It is difficult to find a logical reason why international standards such as treadmill velocity of $2 \mathrm{mph}$ $\left(3.2 \mathrm{~km} \mathrm{~h}^{-1}\right)$ and a treadmill slope of $12.5 \%$ $\left(7.1^{\circ}\right)$ should not be used. Apart from this, internationalisation of the test conditions has the advantage of facilitating comparison of study results.

3. Using walking stability as a criterion, the duration of disease should be at least 12 months rather than 6 , in order to reduce the possibility of walking distance improvements arising from spontaneous collateralisation.

4. Cameron et al. (1988) propose a double-blind phase of 2-4 months. However, we would prefer an observation phase of at least 6 months, as required under EC guidelines (EC guidelines, 1984).

5. The use of a crossover design in patients with unsteady chronic progressive disease is only warranted, if a carryover-effect can definitely be ruled out. This will require a wash out period which may well extend over several months, which seems hardly practical.

A placebo-controlled double-blind study of oxpentifylline using the above criteria has been completed and a manuscript has been submitted for publication.

\section{K.-H. LABS}

Department of Clinical Research Hoechst AG Werk Albert D-6200 Wiesbaden 12, FRG

Received 14 February 1989 , accepted 2 May 1989

Gillings, D., Koch, G., Reich, T. \& Stager, W. J. (1987). Another look at the pentoxyfylline efficacy data for intermittent claudication. J. clin. Pharmac., 27, 601-609.

Porter, J. M., Cutler, B. S., Lee, B. Y., Reich, T., Reichle, F. A., Scogin, J. T. \& Strandness, D. E. (1982). Pentoxifylline efficacy in the treatment of intermittent claudication. Multicenter controlled double-blind trial with objective assessment of chronic occlusive arterial disease patients. Am. Heart J., 104, 66-72.

Roessner, M. \& Mueller, R. (1987). On the assessment of the efficacy of pentoxifylline. J. Med., 18, 1-15. 